\title{
Cerrahi Yoğun Bakım Ünitesinde Çok ilaca Dirençli Acinetobacter Baumannii Enfeksiyonunun Ön Belirleyicileri: Retrospektif Bir Analiz
}

\author{
Predictors of Multidrug Resistant Acinetobacter Baumannii \\ Infections in Surgical Intensive Care Patients: A Retrospective Analysis
}

Aynur Camkıran, Aycan Kundakcı, Coşkun Araz, Arash Pirat, Pınar Zeyneloğlu, Hande Arslan*, Gülnaz Arslan Başkent Üniversitesi Tıp Fakültesi, Anesteziyoloji Anabilim Dalı, Ankara, Türkiye Başkent Üniversitesi Tıp Fakültesi, Enfeksiyon Hastalıkları ve Klinik Mikrobiyoloji Anabilim Dalı, Ankara, Türkiye

\section{ÖZET}

Amaç: Günümüzde hastane kaynaklı enfeksiyonlarda sık rastlanan bir etken olan çok ilaca dirençli Acinetobacter baumannii (ÇID-A. baumannii) artmış morbidite ve mortalite ile ilişkilidir. Bu çalışmada cerrahi yoğun bakım hastalarında ÇID-A. baumannii enfeksiyonu için ön belirleyicilerin belirlenmesi amaçlandı.

Materyal ve Metod: Ocak 2008 ile Ağustos 2010 tarihleri arasında cerrahi yoğun bakım ünitesinde izlenen hastaların verileri retrospektif olarak tarandı. Çok ilaca dirençli A. baumannii enfeksiyonu olan hastalar ve kontrol grubunu oluşturan aynı dönemde yoğun bakımda izlenen ancak ÇID-A. baumannii enfeksiyonu olmayan hastaların yaş, cinsiyet, Acute Physiology and Chronic Health Evaluation II (APACHE II) skoru, Glasgow koma skoru, yandaş hastalıkları, yoğun bakım ünitesine yatış nedeni, ameliyat olanların ameliyat türleri, uygulanan invazif işlemler (entübasyon, arteriyel, santral venöz ve üriner kateterizasyonlar), renal replasman tedavi gereksinimi, üreme yeri, sistem yetmezlikleri, hospitalizasyon ve yoğun bakım ünitesinde kalış süresi, laktat seviyesi ve beyaz küre sayısı kaydedildi. Bulgular: Araştırılan dönem içerisinde 25 hastada ÇID-A. baumannii enfeksiyonu saptandı. Çok ilaca dirençli $A$. baumannii enfeksiyonu olmayan eşleştirilmiş kontrol grubu $(n=25)$ ile karşılaştıııldığında enfeksiyonu olan grupta ortalama APACHE II skoru daha yüksek $(p=0,001)$ ve solunum sistemi hastalığı $(p=0,03)$, açık yara bulunması $(p=0,002)$, mekanik ventilasyon intiyacı $(p=0,005)$ ve

\section{SUMMARY}

Objective: Multidrug resistant Acinetobacter baumannii (MRAB) is an important cause of hospital acquired infection and leads to an increasing morbidity and mortality in intensive care units (ICU). The aim of this study was to investigate the predictors of MRAB infection in surgical ICU patients.

Material and Method: The charts of the patients who were admitted to the ICU between January 2008 and August 2010 were reviewed to identify patients with MRAB infection. Recorded data were as follows: age, sex, medical history, underlying surgical pathology, Acute Physiology and Chronic Health Evaluation II score (APACHE II) and Glasgow Coma Score on ICU admission, presence of invasive procedures (intubation, arterial, central venous lines, urinary catheters, and renal replacement therapy), days in ICU and white blood cells (WBC) and lactate count on infection day, infection site, complications (such as organ/system failure), length of stay (LOS) in the ICU and hospital, and final outcome.

Results: During the study period 25 patients with MRAB infection were identified. When compared with their matched control group $(n=25)$, patients with MRAB infection had a significantly higher mean APACHE II score $(p=0.001)$ and more frequently had an open wound $(p=0.002)$ or required mechanical ventilation $(p=0.005)$, with respiratory system disease $(p=0.03)$, arterial catheterization $(p=0.006)$, and central venous catheterization $(p=0.004)$. Multivariate

Yazışma Adresi/Address for Correspondence: Dr. Aynur Camkıran, Başkent Üniversitesi Tıp Fakültesi, Anesteziyoloji Anabilim Dalı, Ankara, Türkiye Tel.: +90 312212 68 68/1172-4 Faks: +90 3122121583 E-posta: acamkiran@gmail.com Geliş Tarihi/Received: 24.02.2011 Kabul Tarihi/Accepted: 19.08.2011

Türk Yoğun Bakım Derneği Dergisi, Galenos Yayınevi tarafından basılmışıı. / Journal of the Turkish Society of Intensive Care, published by Galenos Publishing. ISNN: 1300-5804 
Türk Yoğun Bakım Derneği Dergisi / Journal of the Turkish Society of Intensive Care 2011;9: 53-8

arteriyel $(p=0,006)$ ile santral venöz kateterizasyonu gereksinimi $(p=0,004)$ daha sıktı. Gruplar arasında anlamlı farklıık gösteren parametreler ile olușturulan lojistik regresyon analizi modelinde APACHE II skoru (OR, 1,155; $\mathrm{Cl}, 1,008-1,324 ; p=0,038$ ) ve açık yaranın varlığı (OR, 27,77; Cl, 2,020-333,333; $p=0,018)$ ÇID-A. baumannii enfeksiyonu için bağımsız risk faktörleri olarak saptandı. Iki grup karşılaştırıldığında ÇlD-A. baumannii ile enfekte olan hastaların yoğun bakım ünitesinde kalış $(36,44 \pm 30,44$ gün ve $7,80 \pm 8,13$ gün, $p<0,001)$ ve hospitalizasyon sürelerinin $(55,12 \pm 40,81$ gün ve $19,04 \pm 13,44$ gün, $p<0,001)$ daha uzun olduğu ve mortaliteleri arasında fark olmadığı görüldü $(\% 56$ ve $\% 32, p=0,154)$.

Sonuç: Bu retrospektif analizin bulguları cerrahi yoğun bakım ünitesi hastalarında yüksek APACHE II skoru ve açık yara varlığının ÇID-A. baumannii enfeksiyonu için ön belirleyici olduklarını göstermektedir. (Türk Yoğun Bakım Derneği Dergisi 2011; 9:53-8)

Anahtar Kelimeler: Çok ilaca dirençli Acinetobacter enfeksiyonu, hastane kökenli enfeksiyon, yoğun bakım ünitesi logistic regression revealed that APACHE $\|$ score $(\mathrm{OR}, 1.155 ; \mathrm{Cl}$, 1.008-1.324; $p=0.038$ ) and open wound $(\mathrm{OR}, 27.77 ; \mathrm{Cl}, 2.020-$ 333.333; $p=0.018$ ) were predictors of MRAB infection in these patients. Compared to their controls, patients with MRAB infection hand a longer LOS in ICU $(36.44 \pm 30.44$ days vs $7.80 \pm 8.13$ days, $p<0.000)$ and hospital $(55.12 \pm 40.81$ days vs $19.04 \pm 13.44$ days, $\mathrm{p}<0.000$ ). In hospital mortality rates for patients with MRAB infection and their controls were $56 \%$ and $32 \%$, respectively $(p=0.154)$.

Conclusion: Our results indicate that APACHE II score and presence of an open wound are predictors of MRAB in ICU surgical patients. Patients with MRAB infection tended to have a higher mortality and had a longer LOS in ICU and hospital than their controls. (Journal of the Turkish Society Intensive Care 2011; 9:53-8)

Key Words: Multidrug-resistant Acinetobacter infection, hospitalacquired infection, intensive care unit

\section{Giriş}

Acinetobacter baumannii (A. baumannii) gram negatif, oksidaz negatif, nonfermentatif kokobasil yapısında bir bakteri olup hastane kökenli enfeksiyonların önemli etkenlerindendir. Bu enfeksiyon, özellikle çok ilaca dirençli hastane enfeksiyonu etkenleri arasında giderek artan oranlarda bildirilmektedir. Çok ilaca dirençli Acinetobacter baumannii (ÇID-A. baumannii) sepsis, üriner sistem ve yara yeri enfeksiyonları, ventilatörle ilişkili pnömoni, menenjit ve endokardit gibi farklı enfeksiyonlara neden olmaktadır $(1,2)$.

Tüm dünyada çok ilaca dirençli bakterilerin neden olduğu hastane kökenli enfeksiyonlar, yüksek mortalite ve kötü klinik seyir ile birliktelik gösterir. Acinetobacter cinsi bakterilerin virülans potansiyelleri düşük olduğundan konak savunma mekanizması normal olanlarda enfeksiyon oluşturması oldukça kısıtıdır. Genellikle fırsatçı hastane enfeksiyonlarına neden olurlar. Nemli ortamları besi yeri olarak kullanan ve bu ortamlarda hızla üreyebilen bir etkendir. Hastalığın ciddiyeti, önceki enfeksiyonlar, yoğun bakım ünitesinde (YBÜ) A. baumannii ile kolonize hasta prevalansının yüksek olması ve kontrolsüz antibiyotik kullanımı A. baumannii enfeksiyonlarının artışında rol oynamaktadır. $(3,4)$ Her yoğun bakım ünitesi için bu ön belirleyicilerin belirlenmesi hem değiştirilebilir ön belirleyicilerin modifikasyonu ile enfeksiyon riskini düşürebilir hem de enfekte hastaların erken tanınması ve başarı için anahtar olan erken tedavi için olanak sağlar.

Bu çalışmada cerrahi YBÜ'de yatan hastalarda ÇID-A. baumannii enfeksiyonunun ön belirleyicilerinin saptanması amaçlandı.

\section{Gereç ve Yöntem}

Bu çalışma Başkent Üniversitesi Tıp ve Sağlık Bilimleri Araştırma Kurulu tarafından onaylanmış (Proje no:KA
10/148) ve Başkent Üniversitesi Araştırma Fonu tarafından desteklenmiştir. Araştırma kurulu onayı alındıktan sonra Ocak 2008-Ağustos 2010 tarihleri arasında cerrahi yoğun bakım ünitesinde yatan hastaların dosyaları retrospektif olarak incelendi. Veriler hastane veri tabanı, hasta dosyaları ve enfeksiyon hastalıkları bölümünün kayıtlarından elde edildi. ÇID- A. baumannii enfeksiyonu olan ve olmayan hastalar 2 grup halinde karşılaştıııldı. Yukarıda belirtilen süre içinde 25 hastada ÇID-A. baumannii üremesi olduğu belirlendi. Kontrol grubu ise aynı süre içinde YBÜ'de yatan ve o dönemde alınan kültürlerinde $A$. baumanni üremesi veya kolonizasyonu olmayan 829 hasta içinden seçildi. Kırk sekiz saatten kısa süre yoğun bakımda yatan hastalar ve yoğun bakım öncesi ÇID-A. baumannii enfeksiyonu veya kolonizasyonu olan hastalar çalışmaya dahil edilmedi. Her iki grupta yer alan hastaların yaş, cinsiyet, Acute Physiology and Chronic Health Evaluation-II (APACHE II) skoru, Glasgow koma skoru (GKS), yandaş hastalıkları, yoğun bakım ünitesine yatış nedenleri, ameliyat olup olmadıkları, hospitalizasyon ve YBÜ'de kalış süreleri kaydedildi. Aynı zamanda hastaların laboratuvar değerleri de incelenerek beyaz küre sayısı ve laktat değerleri kaydedildi. Her iki grupta yer alan hastalarda yoğun bakıma kabullerinde mekanik ventilatör intiyaçları ve uygulanan invazif işlemler (entübasyon ve arteriyel, santral venöz ve üriner kateterizasyonlar) ile renal replasman tedavi intiyacı kaydedildi.

Hastaların enfeksiyon ile ilgili tanı, antibiyoterapinin düzenlenmesi ve gerektiğinde izolasyon uygulanması konularında kararlar enfeksiyon hastalıkları bölümü ile yoğun bakım ekibi tarafından verildi. Aminoglikozit, sefepim ve piperasilin-tazobaktam üçlüsü veya bu üçlüye ek olarak daha fazla antibiyotik direnci bulunan suşlar Ç ID-A. baumannii olarak kabul edildi. Mueller Hinton agar ile antibiyogram duyarllıklarına bakıldı. Phoenix (Becton Dickinson) otomatize identifikasyon sistemi kullanıldı. Sepsis uzlaşı konferansı kriterleri kullanıldı. Kalp hızı >90/dakika, solunum sayısı >20/dakika, 
vücut sıcaklığı $>38{ }^{\circ} \mathrm{C}$ veya $<36{ }^{\circ} \mathrm{C}$ ve lökosit sayısının $<4000 / \mathrm{mm}^{3}$ veya $>12.000 / \mathrm{mm}^{3}$ olması, kriterlerinden 2 veya daha fazlasıyla birlikte enfeksiyonu olan hastalar sepsis olarak kabul edildi. Hastaların izlenmesi National Nosocomial Infections Surveillance System önerilerine göre hasta ve laboratuvar verileri beraber değerlendirilerek, tanımlamalar ise Centers for Disease Control and Prevention kriterlerine göre yapıldı. Enfeksiyonlar hastaneye yatıştan 72 saat ve taburculuk sonrası 10 gün içinde saptanmışsa hastaneden edinilmiş olarak kabul edildi $(5,6)$.

Tablo 1. Hastaların demografik özellikleri ve eşlik eden hastalıkları ([ortalama \pm standart sapma veya sayı (\%)

çiD-A. çiD-A. P

baumannii (+) baumannii (-) Değeri $(n=25) \quad(n=25)$

\begin{tabular}{lccc}
\hline Yaş (yıl) & $65,3 \pm 15,6$ & $64,0 \pm 16,3$ & 0,765 \\
Erkek & $11(\% 56)$ & $14(\% 44)$ & 0,40
\end{tabular}

Eşlik eden hastalıklar

Diabetes mellitus

$7(\% 28)$

$14(\% 56)$

0,23

Solunum sistemi

$4(\% 16)$

7 (\%28)

1

Santral sinir sistemi

$4(\% 16)$

$0(\% 0)$

0,03

Malignite

$7(\% 28)$

$2(\% 8)$

0,38

Renal sistem

$10(\% 40)$

$13(\% 52)$

0,08

$11(\% 44)$

0,77

Tablo 2. Hastaların YBÜ'ye kabul endikasyonları [sayı (\%)]

ÇiD-A. ÇiD-A. $\quad P$

baumannii (+)baumannii (-) değeri $(n=25) \quad(n=25)$

Bilinç durumunda değişiklik

Solunum sıkıntısı

$(\% 4)$

$3(\% 12)$

0,30

Hemodinamik yakın takip

$2(\% 8)$

$6(\% 24)$

0,35

Majör cerrahi sonrası

$8(\% 32)$

$3(\% 12)$

0,63

postoperatif izlem

$11(\% 44)$

0,38

Ciddi sepsis

$2(\% 8)$

$3(\% 12)$

$1(\% 4)$

Kardiyopulmoner resüsitasyon

$1(\% 4)$

0,55

0,30

Tablo 3. Hastaların YBÜ'ye kabul edilldikleri sıradaki değerleri (ortalama \pm standart sapma)

çiD-A.

ÇiD-A.

$P$

baumannii (+) baumannii (-) Değeri

$(\mathrm{n}=\mathbf{2 5})$ $(n=25)$

\begin{tabular}{llll}
\hline Glaskow koma skoru $\quad 10,88 \pm 3,15$ & $14,12 \pm 2,43$ & 0,000
\end{tabular}

APACHE II skoru $\quad 27,12 \pm 6,71 \quad 20,92 \pm 6,74 \quad 0,002$

$\begin{array}{llll}\text { Beyaz küre sayısı }\left(\mathrm{bin} / \mathrm{mm}^{3}\right) & 17403 \pm 27019 & 15231 \pm 9592 & 0,709\end{array}$

Laktat (mmol/lt) 2,15 $\quad 2,21 \quad 2,47 \pm 1,93 \quad 0,524$

Acute Physiology and Chronic Health Evaluation II (APACHE II) skoru

\section{İstatistiksel analiz}

Toplanan verilerin analizi SPSS 17 istatistik programı (SPSS Inc., Chicago, IL, USA) kullanılarak yapıldı. Sürekli değişkenler için ortalama \pm standart sapma ve kategorik değişkenler için sayı (\%) kullanııdı. Çalışmada oluşturulan iki grup verileri ki-kare ve Mann-Whitney $U$ testleri kullantlarak karşılaştırıldı. Klinik ve istatistiksel olarak anlamlılık gösteren değişkenler ile uzamış yoğun bakım kalış süresi ön belirleyicilerini belirleyebilmek amacıyla lojistik regresyon analizi yapıldı. Veriler, ortalama değerler \pm standard deviasyon veya sayı (\%) olarak gösterildi. P değerinin 0,05'ten küçük olması anlamlı kabul edildi.

\section{Bulgular}

Çalışmanın yapıldığı süre içinde 854 hasta YBÜ'de takip edildi. Bu dönem için ÇID-A. baumannii enfeksiyonu oranı 27,4/1000 YBÜ günü olarak hesaplandı. Grupların demografik özellikleri ve eşlik eden sistemik hastalıkları Tablo 1'de verilmiştir. ÇID-A. baumannii (-) olanlara göre ÇID-A. baumannii (+) olan hastalarda solunum sistemi hastalıklarına daha sık rastlandı $(p=0,03)$.

Enfekte grupta 16 hastanın (\%64), enfekte olmayan grupta ise 13 hastanın (\%52) postoperatif dönemde YBÜ'ye kabul edildikleri görüldü $(p=0,39)$. Hastaların YBÜ'ye kabul endikasyonları arasında fark yoktu (Tablo 2).

ÇID-A. baumannii (-) hastalara göre ÇID-A. baumannii (+) hastaların ortalama APACHE II ve Glasgow koma skorları daha yüksek ve YBÜ'ye kabul edilmeden önce hastanede yatış süresi daha uzun bulundu (sırasıyla $p=0,002$, $p=0,000$ ve $p=0,049$, Tablo 3).

Hastalara enfeksiyon gelişmeden önce uygulanan invazif işlemlere bakıldığında ise arteriyel, santral venöz kateterizasyon ve mekanik ventilasyon ihtiyacının enfekte grupta daha sık olduğu (sırasıyla $p=0,005, p=0,003$ ve $p=0,005$ ), abdominal drenaj kateteri, idrar sondası ve uygulanan renal

Tablo 4. Hastaların enfeksiyon gelişmeden önce YBÜ'de kalış süreleri ve uygulanan invazif işlemler [ortalamatstandart sapma veya sayı (\%)].

\begin{tabular}{lccc} 
& $\begin{array}{c}\text { çiD-A. } \\
\text { baumannii (+) } \\
(\mathbf{n = 2 5 )}\end{array}$ & $\begin{array}{c}\text { çiD-A. } \\
\text { baumannii (-) } \\
(\mathbf{n}=\mathbf{2 5})\end{array}$ & $\begin{array}{c}\mathbf{P} \\
\text { Değeri }\end{array}$ \\
\hline Arteriyel kateterizasyon & $22(\% 88)$ & $13(\% 52)$ & 0,005 \\
Santral venöz kateterizasyon & $21(\% 84)$ & $11(\% 44)$ & 0,003 \\
Mekanik ventilasyon intiyacı & $18(\% 72)$ & $8(\% 32)$ & 0,005 \\
Abdominal drenaj kateteri & $12(\% 48)$ & $6(\% 24)$ & 0,077 \\
İdrar sondası & $22(\% 88)$ & $18(\% 72)$ & 0,157 \\
Renal replasman tedavisi & $8(\% 32)$ & $6(\% 24)$ & 0,529 \\
YBÜ'de kalış süreleri & $8,75 \pm 8,00$ & $0,11 \pm 0,45$ & 0,000 \\
Açık yara & $10(\% 40)$ & $1(\% 4)$ & 0,001 \\
\hline
\end{tabular}


replasman tedavi arasında fark görülmezken (sırasıyla $p=0,077, p=0,157$ ve $p=0,559)$ ÇID-A. baumannii (+) olanlarda açık yaraya daha sık rastlandı $(p=0,001)$ (Tablo 4).

ÇID-A. baumannii'nin neden olduğu enfeksiyonlara bakıldığında en sık pnömoniye $(n=16, \% 64)$ rastlanırken yara yeri enfeksiyonu ( $n=6, \% 24)$, idrar yolu enfeksiyonu $(n=2, \% 8)$ ve sepsis $(n=1, \% 4)$ saptanan diğer enfeksiyonlar idi (Tablo 5). Hastane ve YBÜ'de kalış süreleri enfekte olan grupta daha uzun bulunurken, mortaliteleri arasında fark bulunmamaktadır ( $p=0,00, p=0,00, p=0,154)$ ( Tablo 6 ).

ÇID-A. baumannii enfeksiyonu için bağımsız ön belirleyicilerin belirlenmesi amacıyla solunum sistemi hastalığlnın varlığı, mekanik ventilasyon intiyacı, vasküler kateterizasyon (arteriyel ve/veya santral venöz kateterizasyon), açık yarası bulunması ve APACHE II gibi değişkenler kullanılarak lojistik regresyon modeli oluşturuldu. Çoklu regresyon sonucunda APACHE II skoru ve açık yara bulunması ÇID-A. baumannii enfeksiyonunun gelişmesi için ön belirleyiciler olarak belirlendi (Tablo 7).

Tablo 5. Üreme yerleri (sayı (\%)

\begin{tabular}{lc} 
Üreme yerleri & Sayı (\%) \\
\hline Kan kültürü & $1(\% 4)$ \\
Idrar kültürü & $2(\% 8)$ \\
Derin trakeal aspirat kültürü & $16(\% 64)$ \\
Yara yeri kültürü & $6(\% 24)$
\end{tabular}

Tablo 6. Hastaların hospitalizasyon ve YBÜ'de kalış süreleri ile mortaliteleri ([ortalama \pm standart sapma veya sayı (\%)].

\begin{tabular}{|c|c|c|c|}
\hline & $\begin{array}{l}\text { ÇiD-A. } \\
\text { baumannii (+) } \\
(n=25)\end{array}$ & $\begin{array}{c}\text { çiD-A. } \\
\text { baumannii (-) } \\
(\mathrm{n}=25)\end{array}$ & $\stackrel{P}{\text { Değeri }}$ \\
\hline $\begin{array}{l}\text { Hospitalizasyon } \\
\text { süresi (gün) }\end{array}$ & $55,12 \pm 40,81$ & $19,04 \pm 13,44$ & 0,000 \\
\hline $\begin{array}{l}\text { YBÜ'de kalış } \\
\text { süresi (gün) }\end{array}$ & $36,44 \pm 30,40$ & $7,80 \pm 8,38$ & 0,000 \\
\hline Mortalite & $\% 56$ & $\% 32$ & 0,154 \\
\hline
\end{tabular}

Tablo 7. Anlamlı çıkan parametrelerin multivaryasyon lojistik regresyonu

\begin{tabular}{lccc} 
Değişkenler & Odds ratio & P değeri & Cl \%95 \\
\hline Solunum sistemi hastalıkları & 0,253 & 0,109 & $0,047-1,358$ \\
Mekanik ventilasyon ihtiyacı & 0,371 & 0,253 & $0,068-2,033$ \\
Intravasküler girişim & 0,647 & 0,713 & $0,064-6,546$ \\
Açı y yara & 27,77 & 0,018 & $2,020-333,333$ \\
APACHE II skoru & 1,155 & 0,038 & $1,008-1,324$
\end{tabular}

Intravasküler girişim (arteriyel ve/veya santral kateterizasyon), Acute Physiology and Chronic Health Evaluation II (APACHE II) skoru

\section{Tartışma}

Bu çalışmanın gerçekleştirildiği dönem içerisinde 1000 YBÜ günü başına düşen ÇID-A. baumannii enfeksiyon hızı 27,4 olarak belirlendi ve en sık rastlanan enfeksiyon pnömoni ( $n=16, \% 64)$ idi. ÇID-A. baumannii enfeksiyonu olan hastalar olmayanlar ile karşılaştırıldığında bu hastalarda solunum sistemi hastalıklarına daha sık rastlandığı (\%16 ve \%0, $\mathrm{p}=0,03)$, APACHE II $(27,12 \pm 6,71$ ve $20,92 \pm 6,74, p=0,002)$ ve GKS $(10,88 \pm 3,15$ ve $14,12 \pm 2,43, p=0,00)$ skorlarının daha yüksek olduğu, daha sık açık yara bulunduğu (\%40 ve \%4, $p=0,001)$ ve vasküler kateterizasyon ( $\% 41$ ve $\% 59, p=0,017)$ ile mekanik ventilasyona $(\% 72$ ve $\% 32, p=0,005)$ daha sık intiyaç gösterdikleri saptandı. Ancak, çoklu lojistik regresyon analizinde bu parametrelerden sadece açık yara bulunması (OR:27,77, Cl:2,020-333,333, p=0,018) ile yüksek APACHE ॥ skorunun (OR: 1,155, Cl: 1,008-1,324, p=0,038) ÇID-A. baumannii için ön belirleyici olduğu belirlendi.

YBÜ'lerde hastane enfeksiyonlarından sorumlu birçok patojen izole edilmektedir. Hastane enfeksiyonlarının türüne göre izole edilen patojenlerin sıklığı farklılık göstermektedir. Bu patojenlerde en önemli sorun antibiyotik direnci ve yllar içinde bu direncin artmasıdır. YBÜ'lerde en sık görülen hastane enfeksiyonları ve oranları ünitelere göre değişiklik gösterir. Sıklıkla pnömoni, üriner sistem enfeksiyonları ve kateter ilişkili kan dolaşımı enfeksiyonları görülmektedir (7).

A. baumannii son yıllarda, başta pnömoniler olmak üzere hastane kaynaklı enfeksiyonların en önemli nedenlerinden biri haline gelmiştir. A. baumannii dünyanın birçok yerinde olduğu gibi ülkemizde de taşıdıkları çok ilaca direnç nedeniyle YBÜ'lerde sorun oluşturmaktadır. Acinetobacter türleri beta-laktam, tetrasiklin, aminoglikozit ve florokinolon gibi farklı antibiyotik gruplarına karşı hızla direnç geliştirebilmektedir $(2,8)$.

Hastanın YBÜ'ye kabulünde bakılan GKS ve APACHE ॥ skoru, hastalığın ciddiyetini gösterir ve uygulanan invazif prosedürlerle birlikte risk faktörü olduğu bilinmektedir.(9). Katsaragakis ve ark.'nın(10) cerrahi YBÜ'de yaptıkları 680 hastalı prospektif çalışmada A. baumannii enfeksiyonu olan hastaların mortalite ön belirleyicileri araştıııımıştır. Bu çalışmada APACHE II skorunun A. baumannii enfeksiyonuna bağlı mortaliteyi etkileyen ön belirleyicilerden biri olduğu gösterilmiştir. Pirates ve ark (11) tarafından yapılan başka bir çalışmada ise YBÜ'de bir A. baumannii salgını olması halinde o sırada yatan hastaların mortalitelerine bakıldığında APACHE ॥ skorunun bağımsız bir risk faktörü olduğunu göstermişlerdir. Bizim çalışmamızda da her iki grupta da hastaların APACHE II skorlarından elde edilen beklenen mortaliteleri ile gerçekleşen mortalitelerinin birbiri ile uyumlu olduğu görüldü. ÇID-A. baumannii ile kolonize 200 hastanın dahil edildiği, Jung ve ark. (12) tarafından yapılan başka bir çalışmada da APACHE 
II skorunun ÇID-A. baumannii kolonizasyonunun enfeksiyona dönüşümünde risk faktörü olduğu vurgulanmıştır.

Yüksek APACHE II skorlarından anlaşılacağı üzere kritik hastalar olmaları, takiplerinde invazif işlemlerin daha sık uygulanmasına neden olmuştur. Burada da enfekte olan grupta APACHE II ve GKS'lerin daha yüksek olduğu görüldü. ÇID-A. baumanni enfeksiyonu YBÜ'de yatan hastaların mortaliteleri veya hastaneden taburculukları ile ilgili önemli bir belirteçtir, bu hastaların taburculuk oranları düşüktür. (4) Eberle ve ark.'nın (13) Acinetobacter enfeksiyonu olan travma hastalarını inceledikleri çalışmalarında YBÜ'de kalış süresinin uzaması ile Acinetobacter enfeksiyonu gelişimi arasında ilişki olduğu gösterilmiştir. Bu çalışmada da ÇIDA. baumannii enfeksiyonunu gelişen hastalarda invazif girişim sıkığı arttığı ve hastaların YBÜ'nde kalış ve hospitalizasyon süresinin uzadığı görülmekle beraber regresyon analizinde fark olmadığı görüldü. Bunun için daha geniş hasta serileri ile çalışma yapılması gerektiğini düşünüyoruz.

Hastaların YBÜ'ye kabullerindeki uygulanan invazif işlemler hastalığın ciddiyeti ile ilgili fikir vermektedir. Arteriyel ve santral venöz kateterizasyon intiyacı olan hastaların YBÜ'de kalış ve hospitalizasyon süreleri daha uzun olmaktadır. Jung ve ark. (13) YBÜ'de Acinetobacter kolonizasyonu olan hastalarda ÇID-A. baumannii ile bakteriyemi gelişiminde rol alan risk faktörlerini inceledikleri çalışmada santral venöz kateterizasyon ve mekanik ventilasyon ihtiyacının ÇID-A. baumannii enfeksiyonunun gelişimi için risk faktörü olduklarını göstermişlerdir. Bu çalışmada ise hasta sayısının kısıtlı olması nedeniyle arteriyel ve santral venöz kateterizasyonun birlikte intravasküler girişimler olarak regresyon analizi yapıldığında risk faktörü olmadığı görüldü. Ancak, bu hastaların mekanik ventilasyon intiyacı daha sık olmaktadır ve hastalara uygulanan invazif işlem sayı ve sıklığı arttıkça ÇıD-A. baumannii infeksiyonu gelişme oranının da arttığı bilinmektedir.

Acinetobacter'lerin özellikle yumuşak doku ve kemik enfeksiyonu yapma özellikleri bilinmektedir. Nemli ortamları besi yeri olarak kullanan ve bu ortamlarda hızla üreyebilen bir etken olduğundan postoperatif dönemde yara yerinde Acinetobacter üreyebilir. Enfekte grubu oluşturan hastaların \%24'ünde yara yerinde üreme olduğu görülmüştür. Bununla birlikte postoperatif kabul edilen hastalarda intraabdominal drenaj kateteri sıkıkla bulunmaktadır. Açık yara ile birlikte drenaj kateterinin bulunması abdominal kavitenin kontaminasyonu ve intraabdominal organların erozyonuna neden olabilmeleri nedeniyle ÇID-A. baumannii enfeksiyonu gelişme olasilığ|nı artıracak gibi düşünülürken, abdominal drenaj kateterinin anlamlı olmadığı görüldü. Cerrahi YBÜ'lerinde amputasyon güdükleri, dekübit ülserleri ve diyabetik yaralar gibi yaralar Acinetobacter'in vücuda giriş yerleridir. (4) Dolayısıyla açık yarası olan hastalarda Acinetobacter enfeksiyonu daha sık görülmektedir. Yoğun bakım ünitesinde Acinetobacter enfeksiyonu ÇID-A. baumannii enfeksiyonuna sıkıkla dönmektedir.
Gulati ve ark.. (14) tarafindan yapılan bir çalışmada yanık YBÜ'de yanık nedeniyle yatmayan hastalarda ÇID-A. baumannii enfeksiyonuna bağı farklı zamanlarda meydana gelen 3 salgında retrospektif olarak hastalar değerlendirilmiş ve açık yara bulunması ile özellikle abdomen duvarının açıkı̆̆ı̆, ÇıD-A. baumanni enfeksiyonu gelişimi arasında ilişki olduğunu göstermişlerdir. Bu çalışmada da açık yarası olan hastalarda ÇIDA. baumannii enfeksiyonu daha sık görülmüştür $(p=0,001)$.

Bu çalışmanın iki temel kısıtııı̆ı vardır. Birincisi, çalışmanın retrospektif oluşu ve elde edilen verilerin hasta ve reanimasyon ünitesi kayıtlarına dayanması, diğer bütün retrospektif çalışmalar gibi, sonuçlarımızın sorgulanabilmesine neden olan en temel kısıllamadır. Diğer önemli bir neden ise hasta sayısının az olması $(n=50)$ ile birlikte kontrol grubunun belirlenmesinde karşılaşılan güçlüktür.

Bu retrospektif analizin bulgularına göre, cerrahi yoğun bakım ünitesi hastalarında yüksek APACHE II skoru ve açık yara varlığı ÇID-A. baumannii enfeksiyonu oluşumunda ön belirleyicidir. Erken amaca yönlendirilmiş tedavi ile ÇID-A. baumannii enfeksiyonu için etkin tedavi modalitesinin sağlanabileceğini düşünüyoruz.

\section{Kaynaklar}

1. Maragakis LL, Perl TM. Acinetobacter baumanni: epidemiology, antimicrobial resistance, and treatment options. Clin Infect Di 2008:46:1254-63.

2. Garnacho-Montero $\mathrm{J}$ and Amaya-Villar R. Multiresistant Acinetobacter baumannii infections: epidemiology and management. Curr Opin Infect Dis 2010;23:332-9.

3. Jung JY, Park MS, Kim SE, Park BH, Son JY, Kim EY, et all. Risk factors for multi-drug resistant Acinetobacter baumannii bacteremia in patients with colonization in the intensive care unit. BMC Infect Dis 2010;10:228-38.

4. Dent LL, Marshall DR, Pratap S, Hulette RB. Multidrug resistant Acinetobacter baumannii: a descriptive study in a city hospital. BMC Infect Dis 2010;10:196-204.

5. Garner JS, Jarvis WR, Emori TG, Horan TC, Hughes JM. CDC definitions for nosocomial infections, 1988. Am J Infect Control 1988;16:128-40.

6. Mangram AJ, Horan TC, Pearson ML, Silver LC, Jarwis WR. Guideline for Prevention of Surgical Site Infection 1999. Centers for Disease and Prevention, (CDC). Hospital Infection Control Practices Advisory Commitee. Am J Infect Control 1999;27:97-132.

7. Ylipalosaari P, Ala-Kokko TI, Laurila J, Ohtonen P, Syrjala $H$. Epidemiology of intensive care acquired infections in a 14-monthprospective cohort study in a single mixed Scandinavian university hospital ICU. Acta Anaesthesiol Scand 2006;50:1192-7.

8. Dizay M, Çağlar Ö, Arman D. Ventilatör llişkili Pnömoni Etkeni Çok ilaca dirençli Acinetobacter Baumannii Suşlarında Sefoperazon-Sulbaktam ile Netilmisin Kombinasyonunun Invitro Sinerjistik Etkisi. ANKEM Derg 2008;22:28-31.

9. Sheng WH, Liao CH, Lauderdale TL, Ko WC, Chen YS, Liu JW, et all. A multicenter study of risk factors and outcome of hospitalized patients with infections due to carbapenem-resistant Acinetobacter baumannii. Int J Infect Dis 2010;14:764-9.

10. Katsaragakis S, Markogiannakis H, Samara E, Pachylaki N, Theodoraki EM, Xanthaki A, et al. Predictors of mortality of Acinetobacter baumannii infections: A 2-year prospective study in a Greek surgical intensive care unit. Am J Infect Control 2010;38:631-5. 
11. Prates CG, Martıns AF,Supertı SV, Lopes FS, Ramos F, Cantarellı VV, et al. Risk factors for 30-day mortality in patients with carbapenem-resistant Acinetobacter baumannii during an outbreak in an intensive care unit. Epidemiol Infect 2011:139:411-8.

12. Jung JY, Park MS, Kim SE, Park BH, Son JY, Kim EY, et al. Risk factors for multi-drug resistant Acinetobacter baumannii bacteremia in patients with colonization in the intensive care unit. BMC Infect Dis 2010;10:228.
13. Eberle B, Schnuriger B, Putty B,Barmparas G, Kobayashi L, Inaba $\mathrm{K}$, et al. The impact of Acinetobacter baumannii infections on outcome in trauma patients: A matched cohort study. Crit Care Med 2010;38:2133-8.

14. Gulati RK, Choudhuri J, FultonC, Chan JD, Evans HL, Lynch JB, Dellit TH. Outbreak of carbapenem-resistant Acinetobacterbaumannii among non-burn patients in a burn intensive care unit. J Hosp Infect 2010;76:357-8. 